\title{
Factors that influence the postural balance on institutionalized elderly: a cross-sectional study
}

\author{
Natalia Moya Rodrigues Pereira', Marcel Jean Pierre Massè Araya', Eduardo Federigui Baisi Chagas², \\ Marcos Eduardo Scheicher 1,3
}

\begin{abstract}
Introduction: Older adults living in Nursing Homes are a complex population, with a high prevalence of dependency in activities of daily living, multimorbidity, polypharmacy, and reduced mobility and poor balance when compared with community-dwelling elderly. Objectives: The aim of this study was to investigate if the postural balance of institutionalized elderly is influenced by the length of institutionalization, age, number of medications, number of falls, body mass index (BMI) and cognitive status. Methods: 98 elderly people living in the three Nursing Homes were evaluated and 45 were included. Were considered the following variables: ages over 60 years old; length of institutionalization, falls in the previous year, anthropometric measurements (height and weight) and cognitive status. The balance was evaluated by Berg Balance Scale (BBS) and by the Short Physical Performance Battery (SPPB). Results: Of all the variables evaluated, only number of medication and BMI had a negative correlation with scores of BBS and SPPB. In the regression analysis, the significant effect of the number of medications on the SPPB and BERG scores was confirmed. Conclusion: Elderly people living in nursing homes have a poor postural balance and the number of medications and BMI contribute significantly to this.
\end{abstract}

Keywords: Nursing Homes, Postural Balance, Polypharmacy, Body Mass Index.

\section{INTRODUCTION}

The United Nations evaluate that the number of people 60 years or older is expected to more than double until $2050^{(1)}$. The number of people living in nursing homes (NHs) is also expected to rise $\mathrm{e}^{(2,3)}$. In Brazil, the institutionalized elderly represented $1.5 \%$ of the elderly population ${ }^{(4)}$. Living in these institutions can promote social isolation and a reduction in mental and physical activities.

Older adults living in $\mathrm{NHs}$ are a complex population, with a high prevalence of dependency in activities of daily living (ADLs), multimorbidity and polypharmacy ${ }^{(5)}$. In addition, other issues are important in this population, such as length of institutionalization, body mass index (BMI), number of falls, number and type of medication among others.

An another characteristic of older people living in $\mathrm{NHs}$ is the reduced mobility and poor balance when compared with community-dwelling elderly ${ }^{(6-8)}$, increasing their risk of falls.

Based on the description above, it is appropriate to acknowledge the relationship of some variables and the postural balance in $\mathrm{NHs}$ residents and, change same questions. Relating these variables, however, remains little explored in the literature.

\section{OBJECTIVE}

The aim of the study was to investigate if the postural balance of institutionalized elderly is influenced by the length of institutionalization, age, number of medications, number of falls, BMI and cognitive status.

\section{METHODS}

\section{Subjects}

A cross-sectional study was conducted between 2016 and 2017 in the city of Marília, São Paulo, Brazil. Was a convenience sample of 98 elderly living at three NHs. Of the 98 participants initially recruited, 53 were withdrawn because they did not meet the inclusion criteria. Thus, a total of 45 elderly people were enrolled in the study. The study design can be seen in Figure 1.

The following inclusion criteria were used: age 60 years or older; living in the NHs; and independent gait (without gait assistance device). The following exclusion criteria were used: cognitive impairment detectable by means of the mini-mental state examination (MMSE), with the follow cutoffs: 20 for illiterates; 25 for schooling level of 1 to 4 years; 26.5 for 5 to 8 years; 28 for 9 to 11 years; and 29 for higher

Corresponding author: Marcos Eduardo Scheicher. Department of Physical Therapy and Occupational Therapy, Faculdade de Filosofia e Ciências/UNESP, Av. Hygino Muzzi Filho, 737, Mirante, 17.525-000 - Marília, SP 005514 34149430. E-mail: marcos.scheicher@unesp.br

${ }^{1}$ Instituto de Biociências, Universidade Estadual Paulista-UNESP, Rio Claro, São Paulo, Brasil.

Full list of author information is available at the end of the article.

Financial support: nothing to declare.

Submission date 02 March 2018; Acceptance date 20 August 2018; Publication date 16 October 2018 
levels of education ${ }^{(9)}$; and factors that interfere with corporal balance, such as: sequelae of neuromusculoskeletal diseases (stroke or Parkinson's disease), uncorrected visual problems, orthostatic hypotension and continuous use of sedatives, antidepressants and hypnotics.

Written informed consent was signed by all patients before enrollment. The study was approved by the Research Ethics Committee of the Faculty of Philosophy and Sciences, Universidade Estadual Paulista (UNESP), Marília, São Paulo, Brazil, and was conducted in accordance with Resolution No. 196/96 of the National Health Council (Protocol 1.779.430).

The data (number and type of medication, length of institutionalization, age and number of falls) were obtained from the medical records of the older adults included in the study. Anthropometric measurements of height and weight were taken on all patients by using a balance/stadiometer. Weight was measured in kilograms and height in centimeters. BMI was calculated with follow formula: weight/height ${ }^{2}$.

\section{Procedures for evaluating postural balance}

The balance was evaluated using clinical tests, including the Berg Balance Scale (BBS) and the Short Physical Performance Battery (SPPB). The BBS was translated, adapted and validated for Brazil ${ }^{(10)}$, and consists of a battery of 14 tasks common to the $A D L s$, which quantitatively evaluate the risk of falls, through observation undertaken by the examiner. The SPPB is designed to measure functional status and physical performance, assessing walking speed, standing balance, and sit-to-stand performance. The SPPB was translated, adapted and validated for Brazilian Portuguese ${ }^{(11)}$.

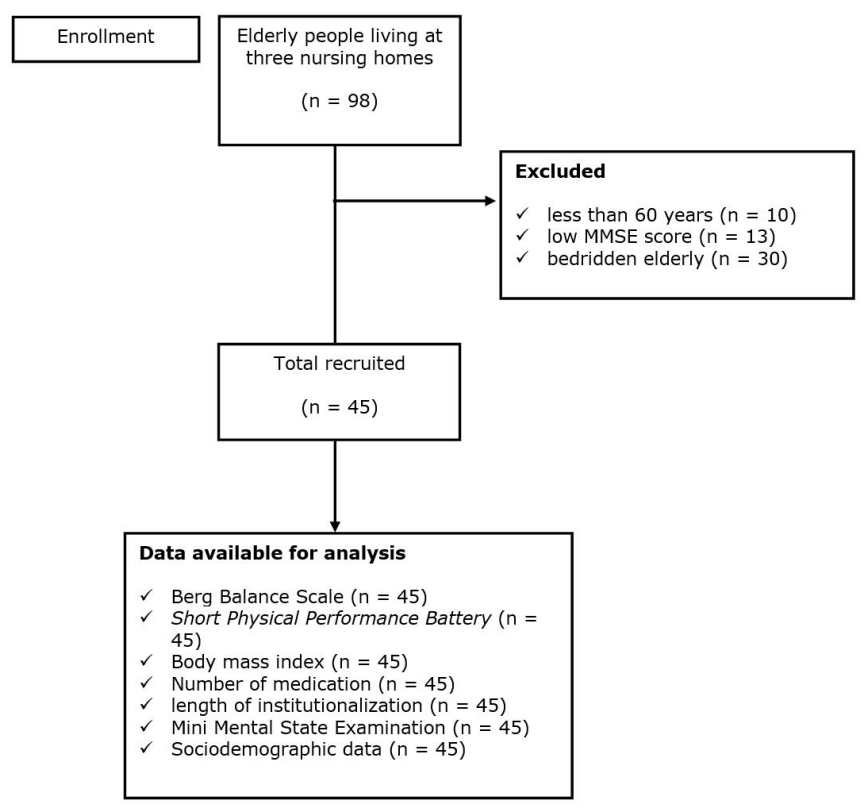

Figure 1: Flow diagram.

\section{Statistical analysis}

Data are described by the mean and standard deviation. The distribution of normality was verified by the Kolmogorov-Smirnov test. To analyze the differences between the genders, the independent t-test or Mann-Whitney test was performed. Fisher's exact test was used to verify the association between antihypertensive and psychotropic medication and the risk of fall and the ODDS RATIO was calculated. Pearson correlation analysis was performed to identify the independent variables with a significant relationship with the dependent variables. The variables that showed significant correlation were initially included in the simple linear regression analysis and later in the multiple regression analysis by the Enter method. The R2 was analyzed to verify the coefficient of determination of the percentage of variation explained by the model. The assumptions of multicollinearity and homoscedasticity were verified. The independent variables that presented $p$ value $>0.05$ were taken from the model. For all analyzes will be used the software SPSS version 19.0 for Windows, being adopted a level of significance of $5 \%$.

\section{RESULTS}

Table 1 shows the mean values of the variables separated by gender. It is possible to observe a significant difference between genders regarding age, number of medication and duration of institutionalization. Of all participants, $93.3 \%$ used some type of medication (Figure 2), such as antihypertensive, psychotropic, antidiabetic and others. The risk of fall was associated with the antihypertensive medication (ODDS RATIO: $10.0 ; p=0.03$ ), but not with the psychotropic medication (ODDS RATIO: 2.37; $p=0.30$ ). Was used a score $\leq 45$ in BBS for greater risk of fall ${ }^{(12)}$

Both the SPPB and BERG scores had a significant and negative correlation with the number of medications and $\mathrm{BMI}$ values (Table 2). In the regression analysis, the significant effect of the number of medications on the SPPB and BERG

Table 1: Comparison of mean and standard deviation of study variables among genders.

\begin{tabular}{|c|c|c|c|c|c|}
\hline & \multicolumn{2}{|c|}{$\operatorname{Man}(n=24)$} & \multicolumn{2}{|c|}{ Woman $(n=21)$} & \multirow{2}{*}{ p-value } \\
\hline & Mean & SD & Mean & SD & \\
\hline Age (year) & 73.25 & 8.22 & 81.10 & 8.31 & $0.003^{*}$ \\
\hline Medication (number) & 4.92 & 3.81 & 7.43 & 3.92 & $0.035^{*}$ \\
\hline $\mathrm{BMI}(\mathrm{kg} / \mathrm{m} 2)$ & 26.95 & 3.54 & 26.55 & 4.22 & 0.733 \\
\hline MMSE (score) & 23.54 & 3.69 & 22.33 & 4.05 & 0.225 \\
\hline LI (months) & 21.46 & 19.10 & 51.14 & 45.34 & $0.001 * *$ \\
\hline SPPB (score) & 8.21 & 2.83 & 6.81 & 2.93 & 0.090 \\
\hline BERG (score) & 49.29 & 6.40 & 46.19 & 9.05 & 0.201 \\
\hline
\end{tabular}

Note: $* \mathrm{p} \leq 0.05$ differences between gender by independent $\mathrm{t}$-test; $* * \mathrm{p} \leq 0.05$ differences between genders by the Mann-Whitney test. BMI: body mass index, MMSE: mini-mental state examination, LI: length of institutionalization, SPPB: Short Physical Performance Battery, BBS: Berg Balance Scale. 


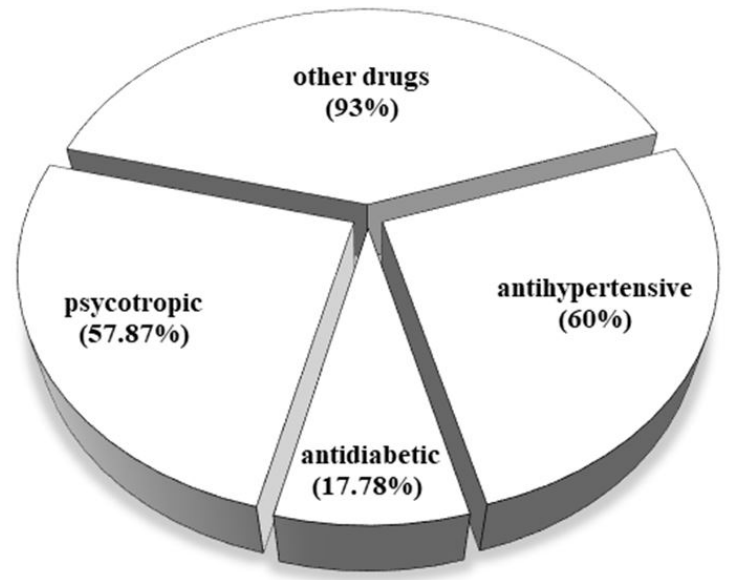

Figure 2: Most common medications used by the nursing home residents of study.

Table 2: Correlation analysis

\begin{tabular}{ccccccc}
\hline & \multicolumn{2}{c}{ SPPB (score) } & & \multicolumn{2}{c}{ BERG (score) } \\
\cline { 2 - 3 } \cline { 6 - 6 } \cline { 5 - 6 } & \multicolumn{1}{c}{$\mathbf{r}$} & p-value & & $\mathbf{r}$ & p-value \\
\hline Gender & -0.241 & 0.111 & & -0.200 & 0.187 \\
Age (year) & -0.243 & 0.108 & & -0.137 & 0.370 \\
Medication (number) & -0.460 & $0.001^{*}$ & & -0.321 & $0.031^{*}$ \\
BMI (kg/m2) & -0.327 & $0.028^{*}$ & & -0.485 & $0.0007^{*}$ \\
MMSE (score) & 0.069 & 0.651 & & 0.188 & 0.217 \\
LI (months) & -0.111 & 0.468 & & 0.020 & 0.898 \\
\hline
\end{tabular}

Note: ${ }^{*} p \leq 0.05$ significant correlation by the Pearson test; $r$ Pearson correlation coefficient. BMI: body mass index, MMSE: mini-mental state examination, LI: length of institutionalization. scores was confirmed, indicating that larger amounts of medication reduce these scores. The number of drugs alone explains $21.1 \%$ (R2) of the SPPB score variation, and $10.3 \%$ (R2) of the BERG score variation, suggesting that the number of medications has a greater effect on the SPPB score. On the other hand, the BMI explains $10.7 \%$ (R2) of the SPPB score variation, and $23.5 \%$ (R2) of the BERG score variation, suggesting that the BMl exerts a greater influence on the BERG score. Together, the number of medication and BMI explain $30.1 \%$ (R2) of the SPPB score variation, and $32.0 \%$ (R2) of the BERG score variation (Table 3).

\section{DISCUSSION}

The aging of the population is growing and because of this, the demand for nursing homes is growing too. The institutionalized population is complex presenting comorbidities, polypharmacy, great intake of drugs and social isolation. One of most problems of this population is the postural imbalance and the occurrence of falls. In this article, we check the influence of length of institutionalization, age, body mass index (BMI), number of medication, cognitive status and gender in two tests of balance: Berg Balance Scale (BBS) and Short Physical Performance Battery (SPPB).

The data showed that of all the evaluated independent variables, only number of medications and BMI showed correlation with the dependent variables (SPPB and BBS) in this population.

Aging is associated with changes in the body, including decreased body water, muscle mass, and bone mass, and with increased fat mass. Some studies report that body fat

Table 3: Regression analysis for dependent variables SPPB (score) and BERG (score)

\begin{tabular}{|c|c|c|c|c|c|c|c|}
\hline \multirow{2}{*}{ Dependent variable } & \multirow{2}{*}{ Independent variable } & \multirow{2}{*}{ B } & \multicolumn{2}{|c|}{$95 \% \mathrm{Cl}$ for $\mathrm{B}$} & \multirow{2}{*}{$\frac{t \text {-test }}{p \text {-value }}$} & \multicolumn{2}{|c|}{ Model } \\
\hline & & & Lower & Upper & & R Square & p-value \\
\hline \multirow[t]{2}{*}{ SPPB (score) } & Constant & 9.594 & 8.148 & 11.040 & $0.0001^{*}$ & 0.211 & $0.001 * *$ \\
\hline & Medication (number) & -0.335 & -0.534 & -0.136 & $0.001 *$ & & \\
\hline \multirow[t]{2}{*}{ SPPB (score) } & (Constant) & 14.237 & 8.236 & 20.239 & $0.0001^{*}$ & 0.107 & $0.028 * *$ \\
\hline & IMC (kg/m2) & -0.250 & -0.472 & -0.028 & $0.028^{*}$ & & \\
\hline \multirow[t]{3}{*}{ SPPB (score) } & (Constant) & 15.654 & 10.215 & 21.093 & $0.0001 *$ & 0.301 & $0.001^{* *}$ \\
\hline & Medication (number) & -0.322 & -0.511 & -0.132 & $0.001^{*}$ & & \\
\hline & $\mathrm{IMC}(\mathrm{kg} / \mathrm{m} 2)$ & -0.229 & -0.429 & -0.030 & $0.025^{*}$ & & \\
\hline \multirow[t]{2}{*}{ BERG (score) } & (Constant) & 51.638 & 47.522 & 55.754 & $0.0001^{*}$ & 0.103 & $0.032 * *$ \\
\hline & Medication (number) & -0.623 & -1.189 & -0.057 & $0.032^{*}$ & & \\
\hline \multirow[t]{2}{*}{ BERG (score) } & (Constant) & 74.287 & 59.462 & 89.112 & $0.0001^{*}$ & 0.235 & $0.001 * *$ \\
\hline & IMC (kg/m2) & -0.988 & -1.537 & -0.440 & $0.001^{*}$ & & \\
\hline \multirow[t]{3}{*}{ BERG (score) } & (Constant) & 76.791 & 62.472 & 91.110 & $0.0001^{*}$ & 0.320 & $0.0001 * *$ \\
\hline & Medication (number) & -0.569 & -1.068 & -0.069 & $0.027^{*}$ & & \\
\hline & IMC (kg/m2) & -0.952 & -1.477 & -0.428 & $0.001 *$ & & \\
\hline
\end{tabular}

Note: $\mathrm{B}$ regression coefficient; $\mathrm{Cl}$ confidence interval for regression coefficient; ${ }^{*} \mathrm{p} \leq 0.05$ significant effect of the regression coefficient of the independent variable; ${ }^{* *} \mathrm{p} \leq 0.05$ significant effect of the model to predict the dependent variable; R2 ratio of variation of dependent variable explained by independent variables SPPB:Short Physical Performance Battery. 
mass can influence balance responses in older people and, in turn, increase the risk of falls ${ }^{(13,14)}$. One study showed the relationship between higher $\mathrm{BMI}$ and risk of falls, indicating that obese had a nonlinear increase in the torque needed to stabilize the body when the ankle torque response was delayed ${ }^{(15)}$. In the nursing home residents, similar to what happening in community-dwelling elders, is experiencing a significant increase in obesity prevalence. Some studies indicated that body weight is positively correlated with postural sway and obesity is associated with increased postural sway in community-dwelling elders ${ }^{(14,16)}$. In our study, the data showed a significant relationship between BMI and SPPB and $\mathrm{BBS}$, indicating that the control of $\mathrm{BMI}$ is an important factor to improve the postural balance in this population ${ }^{(17)}$.

On the other hand, we founded a negative relationship between number of drugs and SPPB and BBS scales. Campbell et al. ${ }^{(18)}$ found that the total number of drugs was an important predictor of falls among women. Nakagawa et al. (2017) founded an association between number of drugs and the risk of falling in community-dwelling elderly ${ }^{(19)}$.

Medications are an essential component of health care for many nursing home residents when are correctly administered, but harmful if not properly indicated. Some risks of polypharmacy for elderly residents are: falls ${ }^{(20,21)}$, fractures ${ }^{(22)}$ and adverse drugs reactions ${ }^{(23)}$. Diverse studies have been published investigating the effect of polypharmacy and specific drug classes on the risk of falls in the community-dwelling elderly ${ }^{(20,21,24)}$, but not in the nursing home residents. In our study the mean of drugs intake per day was $6.08 \pm 4.02$, varying between none and fifteen. The amount was higher in women than in men ( $7.43 \pm 3.92$ and $4.92 \pm 3.81$, respectively; $p=0.0035$ ). There was an association between use of antihypertensive medication and low scores of BBS (ODDS RATIO: 10.0; $p=$ $0.03)$. In theory, cardiac medications can increase the risk of falls through effects on postural blood pressure and because many cardiac medications have the potential to induce cardiac arrhythmias.

The risk of adverse drug events (ADE) increases significantly when the number of consumed medications is 5 or higher ${ }^{(25)}$. In our study, the mean score of BBS to elderly that intake 5 or more medications/day was $45.66 \pm 8.35$, whilst was $51.11 \pm 5.69$ for elderly that intake four or fewer drugs a day $(p=0.004)$. For the SPPB, the same was seen, with higher values for the elderly who ingested four or fewer drugs per day than those who took five or more medications per day $(p=0.001)$.

These results show that it is necessary to control the number of drugs prescribed for this population avoiding/decreasing prescriptions whose benefits are generally outweighed by their potential risks.

\section{CONCLUSION}

The results allow us to conclude that elderly people living in nursing homes have a poor postural balance and that the number of medications and body mass index contribute significantly to this. In addition, the type of medication used also interferes with the postural balance.

\section{AUTHOR'S CONTRIBUITIONS}

NMRP: recruiting participants, collecting data and developing the article. MJPMA: recruitment of participants, data collection and article development. EFBC: Guidance in data collection and statistical analysis. MES: orientation in data collection, statistical analysis and article development.

\section{CONFLICT INTEREST}

Nothing to declare.

\section{AUTHORS DETAILS}

2 Universidade de Marília-UNIMAR, Marília, São Paulo, Brasil. efbchagas@ hotmail.com. 3 Faculdade de Filosofia e Ciências, UNESP, Marília, São Paulo, Brasil.marcos.scheicher@unesp.br

\section{REFERENCES}

1. United Nations. World Population Ageing 2013 [Internet]. 2013 [cited 2018 Jun 7]. Available from: http://www.un.org/en/development/desa/ population/publications/pdf/ageing/WorldPopulationAgeing2013.pdf

2. Pickard L, Comas-Herrera A, Costa-Font J, Gori C, di Maio A, Patxot C, et al. Modelling an entitlement to long-term care services for older people in Europe: projections for long-term care expenditure to 2050. J Eur Soc Policy. 2007 Feb 24;17(1):33-48.

3. de Meijer CAM, Majer IM, Koopmanschap MA, van Baal PH. Forecasting lifetime and aggregate long-term care spending: accounting for changing disability patterns. Med Care. 2012 Aug;50(8):722-9.

4. Camarano A. Brazilian Population Ageing: Differences in well-being by rural and urban areas. 2015. Available from: http://repositorio.ipea.gov. br/bitstream/11058/4962/1/DiscussionPaper_113.pdf

5. de Souto Barreto P, Lapeyre-Mestre M, Mathieu C, Piau C, Bouget C, Cayla $\mathrm{F}$, et al. A multicentric individually-tailored controlled trial of education and professional support to nursing home staff: research protocol and baseline data of the IQUARE study. J Nutr Health Aging. 2013 Feb 15;17(2):173-8.

6. Faber LM. Comparação do equilíbrio estático e mobilidade entre idosos institucionalizados e idosos moradores da comunidade. Universidade Estadual Paulista - UNESP; 2017. Available from: https://repositorio. unesp.br/bitstream/handle/11449/150340/faber_Im_me_rcla. pdf? sequence $=8$ \&isAllowed $=y$

7. Nitz JC, Josephson DL. Enhancing Functional Balance and Mobility Among Older People Living in Long-Term Care Facilities. Geriatr Nurs (Minneap). Mosby, Inc.; 2011 Mar;32(2):106-13.

8. Álvarez Barbosa F, del Pozo-Cruz B, del Pozo-Cruz J, Alfonso-Rosa RM, Sañudo Corrales B, Rogers ME. Factors Associated with the Risk of Falls of Nursing Home Residents Aged 80 or Older. Rehabil Nurs. 2016 Jan;41(1):16-25.

9. Brucki SMD, Nitrini R, Caramelli P, Bertolucci PHF, Okamoto IH. Sugestões para o uso do mini-exame do estado mental no Brasil. Arq Neuropsiquiatr. 2003 Sep;61(3B):777-81.

10. Miyamoto ST, Lombardi Junior I, Berg KO, Ramos LR, Natour J. Brazilian version of the Berg balance scale. Brazilian J Med Biol Res. 2004 Sep;37(9):1411-21.

11. Nakano MM. Versão Brasileira da Short Physical Performance Battery - SPPB: Adaptação Cultural e Estudo da Confiabilidade. Vol. 53. 2013. Available from: http://repositorio.unicamp.br/bitstream/ REPOSIP/252485/1/Nakano_MarciaMariko_M.pdf

12. Nnodim JO, Yung RL. Balance and its Clinical Assessment in Older Adults - A Review. J Geriatr Med Gerontol. 2015;1(1):1-19.

13. Greve J, Alonso A, Bordini ACPG, Camanho GL. Correlation between body mass index and postural balance. Clinics. 2007;62(6):717-20. 
14. Teasdale N, Hue O, Marcotte J, Berrigan F, Simoneau M, Doré J, et al. Reducing weight increases postural stability in obese and morbid obese men. Int J Obes. 2007;31(1):153-60.

15. Corbeil P, Simoneau M, Rancourt D, Tremblay A, Teasdale N. Increased risk for falling associated with obesity: mathematical modeling of postural control. IEEE Trans Neural Syst Rehabil Eng. 2001 Jun;9(2):126-36.

16. Hue O, Simoneau M, Marcotte J, Berrigan F, Doré J, Marceau P, et al. Body weight is a strong predictor of postural stability. Gait Posture. 2007 Jun;26(1):32-8.

17. Zanandrea V, Barreto de Souto P, Cesari M, Vellas B, Rolland Y. Obesity and nursing home: A review and an update. Clin Nutr. Elsevier Ltd; 2013;32(5):679-85.

18. Campbell AJ, Borrie MJ, Spears GF. Risk Factors for Falls in a CommunityBased Prospective Study of People 70 Years and Older. J Gerontol. 1989 Jul 1;44(4):M112-7.

19. Nakagawa HB, Ferraresi JR, Prata MG, Scheicher ME. Postural balance and functional independence of elderly people according to gender and age: cross-sectional study. Sao Paulo Med J. 2017;135(3):260-5.
20. Leipzig RM, Cumming RG, Tinetti ME. Drugs and Falls in Older People: A Systematic Review and Meta-analysis: I. Psychotropic Drugs. J Am Geriatr Soc. 1999 Jan;47(1):30-9.

21. Leipzig RM, Cumming RG, Tinetti ME. Drugs and falls in older people: a systematic review and meta-analysis: II. Cardiac and analgesic drugs. J Am Geriatr Soc. 1999;47(1):40-50.

22. French DD, Campbell R, Spehar A, Cunningham F, Foulis P. Outpatient Medications and Hip Fractures in the US. Drugs Aging. 2005;22(10):877-85.

23. Beers MH, Baran RW, Frenia K. Drugs and the elderly, Part 2: Strategies for improving prescribing in a managed care environment. Am J Manag Care. 2001 Jan;7(1):69-72.

24. Woolcott JC. Meta-analysis of the Impact of 9 Medication Classes on Falls in Elderly Persons. Arch Intern Med. 2009;169(21):1952-60.

25. Johnell K, Klarin I. The relationship between number of drugs and potential drug-drug interactions in the elderly: a study of over 600,000 elderly patients from the Swedish Prescribed Drug Register. Drug Saf. 2007;30(10):911-8. 